OPEN ACCESS

Edited by:

Bruno M. Simões,

The University of Manchester,

United Kingdom

Reviewed by:

Rakesh Kumar,

Rajiv Gandhi Centre for Biotechnology,

India

Cyril Ribeyre,

Centre National de la Recherche

Scientifique (CNRS), France

*Correspondence:

Angela Nebbioso

angela.nebbioso@unicampania.it

${ }^{\dagger}$ These authors have contributed equally to this work

Specialty section:

This article was submitted to Breast Cancer,

a section of the journal

Frontiers in Oncology

Received: 30 July 2021 Accepted: 13 October 2021 Published: 28 October 2021

Citation:

Varghese B, Del Gaudio N, Cobellis $G$, Altucci $L$ and Nebbioso A (2021) KDM4

Involvement in Breast

Cancer and Possible

Therapeutic Approaches.

Front. Oncol. 11:750315. doi: 10.3389/fonc.2021.750315

\section{KDM4 Involvement in Breast Cancer and Possible Therapeutic Approaches}

\author{
Benluvankar Varghese ${ }^{1 \dagger}$, Nunzio Del Gaudio ${ }^{1 \dagger}$, Gilda Cobellis ${ }^{1 \dagger}$, Lucia Altucci ${ }^{1,2}$ \\ and Angela Nebbioso ${ }^{1,3 *}$
}

${ }^{1}$ Department of Precision Medicine, University of Campania Luigi Vanvitelli, Napoli, Italy, ${ }^{2}$ Biogem Institute of Molecular Biology and Genetics, Ariano Irpino, Italy, ${ }^{3}$ Saint Camillus International University of Health and Medical Sciences, Rome, Italy

Breast cancer (BC) is the second leading cause of cancer death in women, although recent scientific and technological achievements have led to significant improvements in progression-free disease and overall survival of patients. Genetic mutations and epigenetic modifications play a critical role in deregulating gene expression, leading to uncontrolled cell proliferation and cancer progression. Aberrant histone modifications are one of the most frequent epigenetic mechanisms occurring in cancer. In particular, methylation and demethylation of specific lysine residues alter gene accessibility via histone lysine methyltransferases (KMTs) and histone lysine demethylases (KDMs). The KDM family includes more than 30 members, grouped into six subfamilies and two classes based on their sequency homology and catalytic mechanisms, respectively. Specifically, the KDM4 gene family comprises six members, KDM4A- $F$, which are associated with oncogene activation, tumor suppressor silencing, alteration of hormone receptor downstream signaling, and chromosomal instability. Blocking the activity of KDM4 enzymes renders them "druggable" targets with therapeutic effects. Several KDM4 inhibitors have already been identified as anticancer drugs in vitro in BC cells. However, no KDM4 inhibitors have as yet entered clinical trials due to a number of issues, including structural similarities between KDM4 members and conservation of the active domain, which makes the discovery of selective inhibitors challenging. Here, we summarize our current knowledge of the molecular functions of KDM4 members in $\mathrm{BC}$, describe currently available KDM4 inhibitors, and discuss their potential use in BC therapy.

Keywords: epigenetics, histone demethylation, KDM4 inhibitors, JMJD2, KDM4

\section{INTRODUCTION}

Breast cancer (BC) is the second leading cause of cancer death in women worldwide with a $0.5 \%$ increase in incidence rate per year. Advances in diagnosis and treatment in $64 \%$ of BC cases at earlier stages has increased 5-year survival to 99\% (National Breast Cancer Foundation).

Much is known about oncogenes, tumor suppressors, and DNA repair genes, which play a role in breast tumorigenesis, promoting aberrant cell growth and/or mismatch error repair $(1,2)$. Research on molecular hallmarks of $\mathrm{BC}$ has identified several diagnostic markers including: 
i) immunohistochemical markers, such as estrogen receptor (ER), progesterone receptor (PR), and human epidermal growth factor receptor 2 (HER2); ii) genetic markers, such as BRCA1, BRCA2, and PIK3CA mutations; iii) immunomarkers, such as programmed death-ligand 1 (PD-L1) and tumor infiltrating lymphocytes; iv) proliferation markers, such as Ki67. All of these have significantly changed the prediction of prognosis and therapy decisions (3).

The Cancer Genome Atlas classifies BC into five different subtypes: normal-like, luminal A, luminal B, HER2-positive $\left(\mathrm{HER} 2^{+}\right)$, and basal-like. Luminal A and B tumors are ER- and PR-positive $\left(\mathrm{ER}^{+} \mathrm{PR}^{+}\right)$, while the HER2 ${ }^{+}$and basal-like subtypes are hormone-independent $\left(\mathrm{ER}^{-} \mathrm{PR}^{-}\right)$and positive for high levels of Ki-67, showing the worst prognosis (4).

Current therapeutic strategies for BC are based on tumor heterogeneity associated with different histotypes and specific molecular profiles: $\mathrm{ER}^{+}$and $\mathrm{PR}^{+}$patients are treated with hormonal therapy, HER2 ${ }^{+}$patients with anti-HER2 therapy, and $B R C A$ mutation carriers with poly (ADP-ribose) polymerase (PARP) inhibitors plus adjuvant therapies (chemotherapy, immunotherapy, and radiation therapy) (5).

Despite advancements in our knowledge of BC biology as well as intense disease prevention programs and therapies able to block tumor progression, the incidence of $\mathrm{BC}$ continues to rise. Highthroughput analysis reveals a massive transcriptional deregulation in $\mathrm{BC}$, for which a tight interplay between genetic and epigenetic factors has been hypothesized. Progressive dedifferentiation of cell identity to a progenitor-like state due to increased cell plasticity is observed in the early phase of cancer formation, whereas epigenetic modifications support oncogenic progression (6).

Epigenetic alterations such as DNA methylation and reversible histone modifications (methylation, acetylation, ubiquitination) alter gene accessibility, resulting in aberrant gene expression.

A promising opportunity to rewind cell fate comes from epigenetic-based therapies, which make use of small molecule drugs (epidrugs) able to interfere with the activity of epigenetic regulators and thus correct cancer-associated chromatin states (7). Following confirmation of the efficacy of epidrug-based therapies in oncology by several in vitro studies, many epidrugs have moved to clinical trials for different cancer types (8), and some have been clinically approved by the US Food and Drug Administration (9).

Eukaryotic chromatin is organized in active euchromatin and inactive heterochromatin and the histone methylations define these two interchangeable functional states. Histone lysine methylation is regulated by methyltransferases (KMTs) and demethylases (KDMs) (10). KDMs are classified into two groups: i) the KDM1 or LSD1 family, dependent on flavin adenine dinucleotide (FAD) and ii) the $\mathrm{JmjC}$ family, dependent on 2-oxoglutarate (2-OG) for their demethylase activity. JmjC domain-containing KDMs form the larger KDM class with 20 members grouped into five subfamilies (KDM2/7, KDM3, KDM4, KDM5, and KDM6), and their deregulation is associated with cancer, including BC (11).
Based on their catalytic activity, KDM4 subfamily members catalyze N-methyl-lysine demethylation by removing mono-, di-, and trimethyl marks via an oxidative mechanism. KDM4 uses 2OG and $\mathrm{O}_{2}$ as cosubstrates, $\mathrm{Fe}(\mathrm{II})$ as a cofactor for the enzymatic oxygenase reaction (Figure 1A). This activity contributes to the control of gene expression in a context-dependent manner, either by influencing the compaction of chromatin or through regulation of signaling pathways and recruitment of other protein complexes. The most frequent modifications occur on $\mathrm{H} 3 \mathrm{~K} 4, \mathrm{H} 3 \mathrm{~K} 36$ and H3K79 associated with gene activation, whereas $\mathrm{H} 3 \mathrm{~K} 9, \mathrm{H} 3 \mathrm{~K} 27, \mathrm{H} 4 \mathrm{~K} 20$ and $\mathrm{H} 3 \mathrm{~K} 56$ associated with gene silencing (11-13).

The KDM4 (JHDM3/JMJD2) subfamily is highly conserved $(14,15)$. In humans, this subfamily comprises $K D M 4 A, K D M 4 B$, $K D M 4 C$, and KDM4D genes, with KDM4E and KDM4F considered as pseudogenes, although a partial catalytic activity is reported (16) (Figure 1B).

KDM4A-C enzymes have five different domains: JmjN, JmjC, tandem PHD, Tudor, and F-box, whereas KDM4D-F lack PHD and Tudor domains (Figure 1B) (17). The stability and catalytic activity of KDM4s depends on the interaction between JmjN and JmjC domains, and their structural integrity maintains overall protein stability (18). The crystal structure of the KDM4A Tudor domain revealed it as histone reader, identifying methylated lysine residues at histone $\mathrm{H} 3$ and $\mathrm{H} 4$ tails; the function of the PHD domain is still unclear, although in other PHD-containing proteins this domain is able to bind modified and unmodified histone residues (19).

Concerning KDM4 mRNA levels, they are tightly regulated to guarantee proper biological processes (20). Next-generation sequencing in normal tissues revealed that $\mathrm{KDM} 4 \mathrm{~A} / \mathrm{B} / \mathrm{C}$ are broadly expressed in most tissues, although at different levels. They share more than $50 \%$ protein sequence identity, however the variations in expression levels suggest that these proteins have not-overlapping functions, as evidenced also by single/ double knockout mouse models, that were viable and showed no evident abnormalities. Cell-specificity is thus guaranteed by specific interaction with regulatory factors. For instance, the control of KDM4A expression rely on ubiquitin-proteasome pathway through FBX022, a key regulator of histone methylation. This evidence suggests that posttranslational modifications of KDM4A regulates its abundance, conferring it the cell/tissue-specificity (21). Other studies suggested that KDM4s have peculiar cell-type functions. Heart-specific KDM4A conditional knockout showed cardiac hypertrophy and no compensatory effect has been observed (22).

KDM4 subfamily members control different biological functions, to ensure proliferation, differentiation, migration and adhesion (23), as well as regulation of transcription (24) and genome stability (25) (Figure 2). In embryonic stem cells (ESCs), KDM4 proteins (4B and 4C) control stem cell identity by interacting with the pluripotency factors such as Sox2, Oct4, cMyc, and Klf4, but also by modulating, alone or in combination, gene expression during the differentiation program (26). In addition, depletion of KDM4C in ESCs causes downregulation 
A

\section{Mechanism of action}
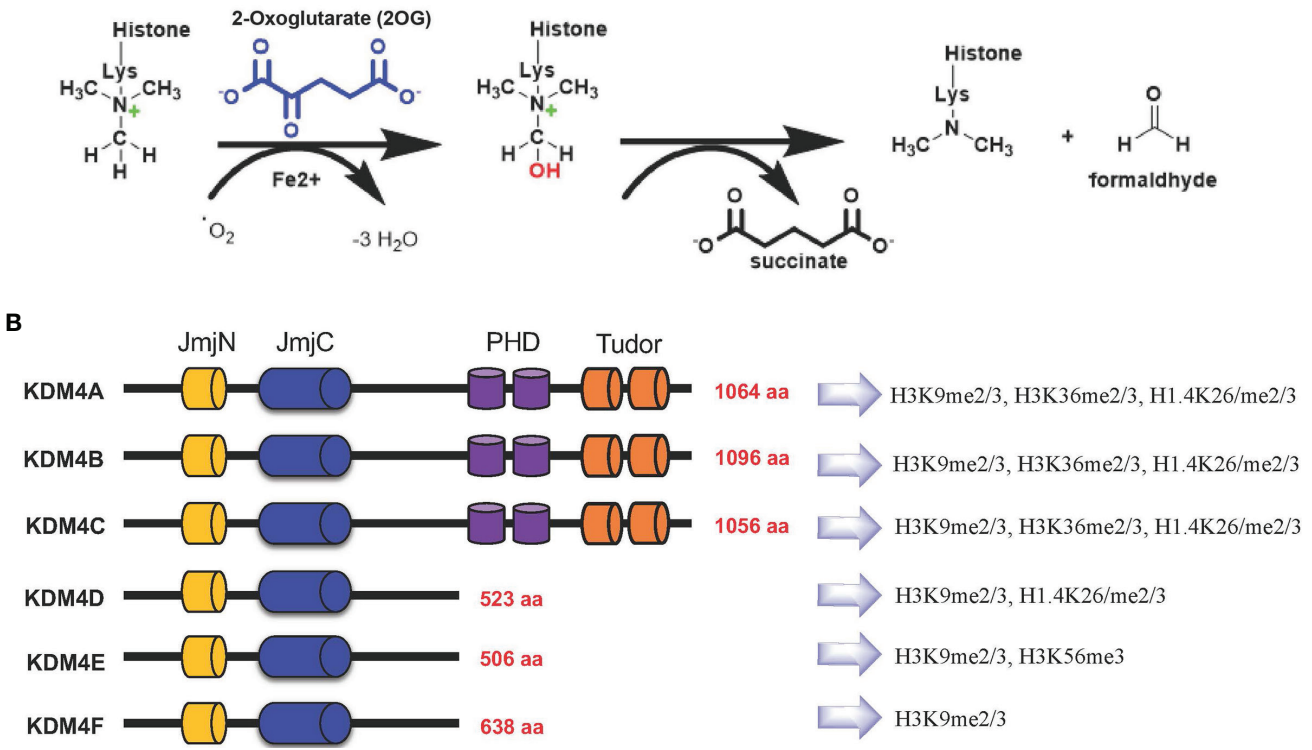

FIGURE 1 | (A) KDM4s: mechanism of demethylation; (B) KDM4s have conserved JmjN and JmjC domains, while substrate recognition domains such as PHD and Tudor are present only in KDM4A-C. Histone targets of KDM4 family members are shown on the right.

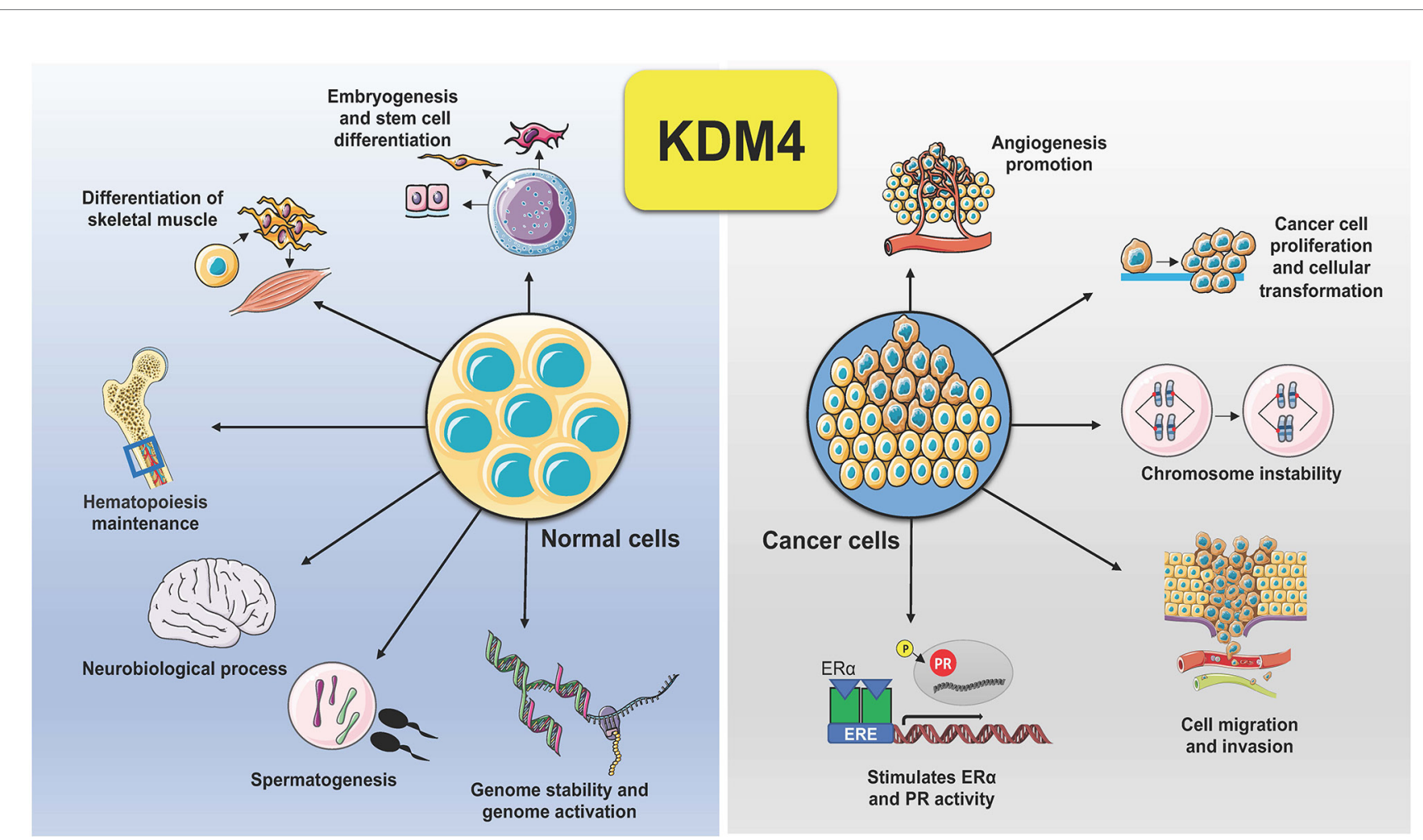

FIGURE 2 | Schematic representation of KDM4 functions in normal and cancer cells. Deregulation of KDM4 promotes cancer cell proliferation, migration, and invasion, angiogenesis, chromosome instability, and stimulation of ER and PR activity. 
of $M y c$ and Klf4 genes associated with cell proliferation during early embryo stage, leading to developmental defects (27).

KDM4s are also involved in cell differentiation: KDM4B promotes osteogenic differentiation of human mesenchymal stem cells, activating expression of $D L X$ genes by removing trimethyl groups from H3K9me3 marks $(28,29)$, whereas depletion of KDM4B reduces osteogenic differentiation via $D L X$ gene suppression (28).

Downregulation of Taf1b and Nom1 in hematopoietic stem cells was observed due to accumulation of $\mathrm{H} 3 \mathrm{~K} 9 \mathrm{me} 3$ on their transcription start sites (30), following knockout of KDM4A/B/C in vivo resulting in aberrant differentiation.

KDM4A was found to play an important role in skeletal muscle differentiation (31), while KDM4B deletion in mice leads to neurodevelopmental disorders and defects in spinal maturation (32). KDM4A knockdown or inhibition decreases leukocyte adhesion and transmigration in inflammatory response, by modulating expression of vascular adhesion proteins (ICAM1 and VCAM1) in cerebral microvessels (33). $\mathrm{KDM} 4 \mathrm{~A} / \mathrm{D}$ play a role in female fertility (34) and in spermatogenesis, respectively (35). KDM4D was recently reported to maintain genome stability by facilitating double-strand DNA damage repair mechanisms in a PARP1-dependent manner; specifically, the interaction between KDM4D and RNA seems to be essential for chromatin localization and efficient demethylation of trimethyl H3K9 (36).

Concerning breast tissue, KDM4B is important for transcriptional regulation and development of mammary gland. Deletion of KDM4B in mammary epithelium produces immature mammary gland development in female mice (37). KDM4B is also involved in ER signaling cascade and is required for ER-mediated gene transcription, essential for normal development of ovarian follicles, luteal function, and ovulation (38-40). In summary, these findings revealed that KDM4B plays a critical role in regulation of transcriptional program in the mammary gland.

Dysregulation of KDM4s is behind several hallmarks of cancer (Figure 2). Tumorigenesis is a complex adaptive process that involves alterations in different cellular functions, as proliferation, differentiation, adaptation to altered microenvironment, many of them controlled by KDM4s, found overexpressed in various human cancers, sustaining tumor progression and acting as oncoproteins $(11,41)$.

Thus, KDM4s have emerged as a druggable targets in cancer to restore cell homeostasis by erasing inappropriate histone modifications distributed across the genome that are responsible of cell transformation. Although the drug discovery rationale is straightforward, the efficacy of KDM4 inhibitors identified to date is limited, mainly due to their lack of selectivity and/or specificity to the different KDM4 isoforms (42).

High expression levels of KDM4A were observed in squamous cell carcinoma as well as in ovarian and prostate cancer, where it is highly associated with chromosomal instability (43). KDM4A/C/D bind androgen receptor (AR) in vitro and in vivo, resulting in tumor cell proliferation through demethylation of $\mathrm{H} 3 \mathrm{~K} 9 \mathrm{me} 3$ in $\mathrm{AR}$ target genes, stimulating $\mathrm{AR}$ dependent transcription in combination with $\operatorname{KDM} 1 \mathrm{~A}(44,45)$.

KDM4A is also directly involved in upregulation of the lung cancer-associated genes CXCL5, ADAM12, and JAG1, involved in angiogenesis promotion, tumor cell growth, and cell proliferation (46-50). Overexpression of KDM4C was found in non-small cell lung carcinoma (51) and osteosarcoma (52), where upregulation of fibroblast growth factor 2, promoted by $\mathrm{KDM} 4 \mathrm{~B} / \mathrm{C}$ modulates cell migration, invasion, and proliferation in osteosarcoma metastasis (52).

Demethylation of H3K9 marks by KDM4D is involved in tumor necrosis factor $\alpha$ activation, associated with tumorigenesis and inflammatory response (53). KDM4D stimulates p53dependent gene expression and acts as a pro-oncogenic factor, specifically on AR target genes in prostate and colon cancer cell growth (54). Further, KDM4A reduces activity of p53 pathway through inhibition of Ras-mediated chromodomain-helicaseDNA-binding protein 5 (CHD5) induction, blocking senescence and thereby promoting cell transformation (55).

In ovarian cancer, reduced levels of KDM4B led to an increase in $\mathrm{H} 3 \mathrm{~K} 9 \mathrm{me} 3$ in the promoter regions of genes such as $P D G F B$, $L C N 2$, and LOXL2, suppressing cell migration, invasion, and formation of spheroids in vitro (56). In gastrointestinal tumors, KDM4D promotes cancer progression by directly interacting with hypoxia-inducible factor (HIF) $1 \beta$ gene and activating its expression via $\mathrm{H} 3 \mathrm{~K} 9 \mathrm{me} 3$ demethylation of the vascular endothelial growth factor A promoter region (57). KDM4B expression was found to be activated by HIF genes, promoting cancer cell survival in a hypoxic setting (58-60).

In conclusion, KDM4s exert their effect mainly by altering the chromatin state and therefore the expression of genes involved in physiological functions that, when disrupted, cancer occurs.

\section{FUNCTIONAL ROLE OF KDM4s IN BREAST CANCER}

KDM4s are responsible in controlling development and proliferation of mammary gland (61), and their altered expression (mainly gene amplification) can promote cell transformation, migration, and invasion, all hallmarks of tumorigenesis in BC (47) (Figure 3). A recent meta-analysis of $\mathrm{KDM} 4$ gene expression in $\mathrm{BC}$ subtypes identified overexpression of $\mathrm{KDM} 4 \mathrm{~A} / \mathrm{D}$ in basal-like BC, whereas KDM4B was predominantly expressed in $\mathrm{ER}^{+}$luminal-type $\mathrm{BC}$ (61).

The development of potential KDM4 inhibitors with high selectivity in different $\mathrm{BC}$ subtypes therefore remains a major challenge. To address this issue, a better understanding of the molecular mechanisms of KDM4s as well as their specific target sites is urgently required to develop new treatments targeting molecular pathways crucial for $\mathrm{BC}$ progression.

\section{KDM4A in BC}

KDM4A mainly demethylates $\mathrm{H} 3 \mathrm{~K} 9 \mathrm{me} 2 / \mathrm{me} 3$ and, at a lower rate, H3K36me2/me3 in vivo and $\mathrm{H} 1.4 \mathrm{~K} 26 \mathrm{me} 3$ in vitro (17), 


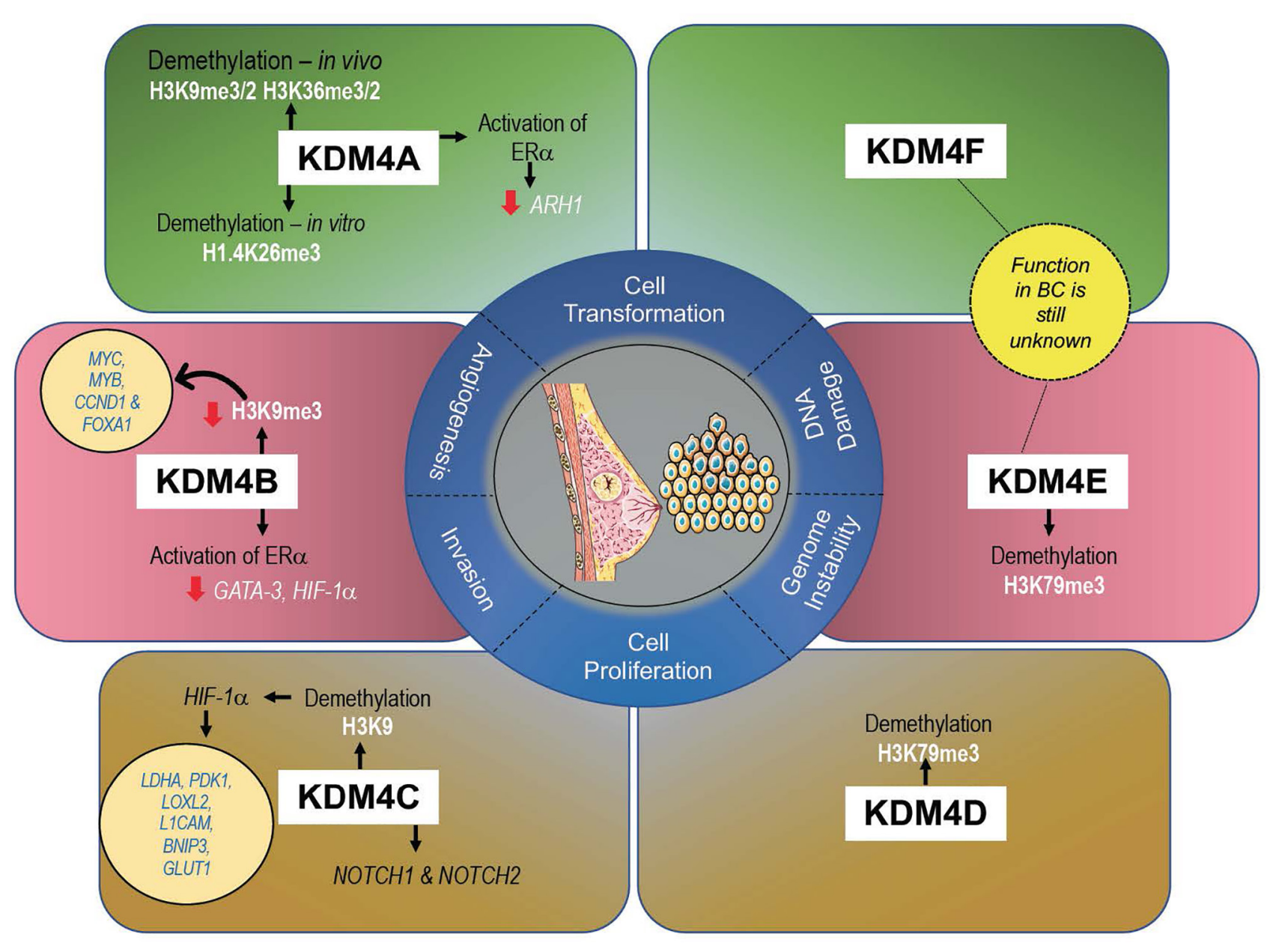

FIGURE 3 | Expression levels of each KDM4 and its histone marks associated with BC progression.

promoting chromatin decompaction. Via histone deacetylase (HDAC) and p53 association, KDM4A may repress gene expression $(62,63)$.

Overexpression of KDM4A was observed in $60 \%$ of $\mathrm{BC}$ tissue at both mRNA and protein level (64). KDM4A overexpression leads to upregulation of estrogen-dependent genes, whereas depletion of KDM4A decreases transcription of ER $\alpha$ target genes, such as JUN and CCND1, promoting cell growth arrest. Taken together, these interconnections suggest that KDM4A promotes $\mathrm{BC}$ growth via hormone-dependent and -independent mechanisms (65). KDM4A overexpression was also found to contribute to $\mathrm{BC}$ growth through downregulation of the tumor suppressor gene ADP-ribosylarginine hydrolase 1 (ARH1), highly expressed in normal breast tissue (66). Furthermore, downregulation of the ubiquitous transcription factor Sp1 was reported in highly invasive and in advanced stages of BC, showing a clear correlation with the TNM staging system, confirmed by KDM4A overexpression (67). In vitro, knockdown of KDM4A in MCF-7 cells blocks JUN expression, inhibiting invasion, migration, and tumor formation (68-70). In these cells, expression levels of KDM4A were also found to be modulated by hsa-mir-23a-3p, hsa-mir-23b-3p, and hsa-mir-137. Inhibition of these microRNAs enhances KDM4A levels, with a consequent increase in some drug-resistant genes such as CDC28 protein kinase regulatory subunit $1 \mathrm{~B}$ (CKS1B) (71), contributing to the outgrowth of chemoresistant cells (68).

$\mathrm{CHD5}$, a tumor suppressor gene, is under the control of KDM4A, whose silencing restores CHD5 expression by decreasing H3K36me2/me3 histone marks in its locus (72).

\section{KDM4B in BC}

KDM4B is similar to KDM4A in structure and enzymatic activity, demethylating both $\mathrm{H} 3 \mathrm{~K} 9$ and $\mathrm{H} 3 \mathrm{~K} 36$. Unlike $\mathrm{KDM} 4 \mathrm{~A} / \mathrm{C}, \mathrm{KDM} 4 \mathrm{~B}$ acts as a monomer and not as a homodimer or heterodimer (73).

$\mathrm{KDM} 4 \mathrm{~B}$ is a key regulator of estrogen signaling cascade, and its depletion attenuates $\mathrm{BC}$ growth both in vitro and in vivo (37, 40 ). Noteworthy, $K D M 4 B$ is itself an ER-responsive gene (58). Taken together, these findings suggest a positive feedback mechanism between KDM4 and ER whereby estrogen-induced KDM4 expression in turn coregulates and, unexpectedly, upregulates ER-target genes, sustaining BC growth. KDM4B is 
required in ER-mediated gene transcription essential not only in mammary gland, but also in ovarian follicles, suggesting a possible correlation of KDM4B between these gynecological cancers.

$\mathrm{H} 3 \mathrm{~K} 4$ methylation and $\mathrm{H} 3 \mathrm{~K} 9$ demethylation are coordinated by binding of KDM4B/mixed-lineage leukemia 2 (MLL2 or KMT2D) complex, with ER $\alpha$ driving ER $\alpha$-dependent transcription (74). Some studies report the interaction of KDM4B/ER $\alpha$ with SWI/SNF-B chromatin complex, regulating numerous genes involved in resistance and invasiveness of $\mathrm{BC}$ (37). Decreased levels of $\mathrm{H} 3 \mathrm{~K} 9 \mathrm{me} 3$, corresponding to overexpression of $\mathrm{KDM} 4 \mathrm{~B}$, facilitate transcription of ERresponsive genes such as $M Y C, M Y B, C C N D 1$ (37), and FOXA1 (40). GATA-3 is a transcription factor highly expressed in luminal A-type BC and is associated with ER expression. The demethylation process mediated by KDM4B is fundamental for activation of ER by GATA-3, whereas downregulation of KDM4B levels induces H3K9 methylation and a reduction in GATA-3 binding on ER promoter, suppressing ER targets (40). Moreover, ER $\alpha$ regulates expression of KDM4B through HIF-1 $\alpha$, promoting its expression in a feedforward regulatory circuit (58).

Several ER coregulated genes are primed to activate gene expression upon histone modifications induced by KDM4 proteins. One example is the KDM3A/KDM4B/FOXA1 complex, which leads to an increase in pro-proliferative and $E R \alpha$-dependent gene expression and dual knockdown of KDM4A and KDM4B, strongly inhibiting ER $\alpha$ activity and blocking cell proliferation (75).

Additionally, high KDM4B-mediated demethylation levels of $\mathrm{H} 3 \mathrm{~K} 9$ were found on the promoter of long interspersed nuclear element-1, increasing its expression and improving the effectiveness of retrotransposition (76). A direct correlation was found between KDM4B expression and the absence of $\mathrm{H} 3 \mathrm{~K} 9 \mathrm{me} 3$ in pericentromeric regions, suggesting the involvement of this enzyme in chromosomal instability and aneuploidy cell formation (77).

Interestingly, KDM4B also plays a role at cytoplasmic level, where it regulates the unfolded protein response (UPR) pathway through direct interaction with eukaryotic initiation factor $2 \alpha$ (eIF2). UPR is commonly hyperactivated as result of severe and prolonged cellular stress, triggering cell death. Inhibiting the association between KDM4B and eIF2 also allows activation of UPR cell death pathway in triple-negative breast cancer (TNBC), deficient in PTEN, and therefore increases responsiveness to therapy with PI3K-AKT inhibitors (78).

Selective estrogen receptor modulators (SERMs) are beneficial in treating premenopausal ER-positive BC resistant to tamoxifen. However, no effect was obtained in tumors where Fbxo22 gene is low expressed as Fbxo22 ubiquitinates tamoxifenbound KDM4B (79), resulting in KDM4B overexpression and poor prognosis.

\section{KDM4C in BC}

KDM4C (also known as GASC1) is amplified in many cancers including $\mathrm{BC}$, mainly in basal-like and in $\mathrm{ER}^{-}$and $\mathrm{PR}^{-}$subtypes (80), making this enzyme a negative prognostic marker $(81,82)$.
KDM4C overexpression is mediated by gene amplification of 9p24 chromosomal region, which contains several candidate tumor genes, including $K D M 4 C$.

$\mathrm{KDM} 4 \mathrm{C}$ regulates expression of genes involved in stem cell self-renewal and induces phenotypic changes in cancer cells. However, despite its involvement in tumor development, proliferation, and aggression, very little is known about this enzyme compared to KDM4A/B. In MCF-10A cells, the expression of KDM4C induces a transformed phenotype (80). KDM4C upregulates many genes responsible for cell growth, migration, and metastasis and interacts with HIF- $1 \alpha$, mediating KDM4C recruitment on hypoxia-inducible genes and demethylation of $\mathrm{H} 3 \mathrm{~K} 9$ on metabolic genes, such as $L D H A$, PDK1, LOXL2, L1CAM, BNIP3, and GLUT1. The physical interaction of these two proteins is a critical epigenetic mechanism, given that HIF-1 $\alpha$ involvement in BC is responsible for an aggressive phenotype, characterized by metastasis progression and resistance to drug therapy (83).

A D396N polymorphism found in the caspase- 3 cleavage site of $K D M 4 C$ in $\mathrm{BC}$ cells and contributes to drug resistance, indicating the involvement of $\mathrm{KDM} 4 \mathrm{C}$ in BC-resistant progression (81).

Unlike KDM4A, KDM4C is recruited to mitotic chromosomes, modulating correct chromosomal stability and gene expression. This suggests that total inhibition of the enzyme in TNBC should induce a reduction in cell multiplication (84) and an increase in $\gamma-\mathrm{H} 2 \mathrm{AX}$, a marker of DNA damage (81). Through modulation of steroid receptor co-activator 1 (SRC-1), KDM4C also regulates $\mathrm{CD} 24$ and the apoptotic protein PAWR. In endocrine-resistant BC cell lines, SRC-1/KDM4C complex together with JUN mediates transcriptional repression of these two oncogenic proteins (85).

Despite evidence that KDM4C silencing or inhibition may represent an effective epigenetic therapy in $\mathrm{BC}$ treatment, a study conducted on 355 patients with invasive BC found that KDM4C was negatively associated with the development of a more aggressive BC histopathological type (grade II/III, ductal-type, $\mathrm{PR}^{-}$, and $\mathrm{ER}^{-}$). Women with KDM4C-positive tumors responded better to radiation therapy and hormone treatment (82).

\section{$\mathrm{KDM} 4 \mathrm{D} / \mathrm{E} / \mathrm{F}$ in $\mathrm{BC}$}

Unlike other subfamily members, KDM4D has JmjN and JmjC domains encoding only a small peptide protein. KDM4D potentially regulates $\mathrm{H} 3 \mathrm{~K} 79 \mathrm{me}$, suggesting its involvement in DNA repair, telomeric silencing regulation, cellular development, transcriptional regulation, and cell cycle checkpoints (86). The role of KDM4D in cancer is relatively less studied than that of other KDM4s. A recent study reported that KDM4D was significantly overexpressed in basal-like BC, with an amplification frequency of $3.6 \%$, and was found ubiquitously expressed in $\mathrm{ER}^{+}, \mathrm{MCF}-10 \mathrm{~A}$, and basal-like cell lines (61).

The catalytic domain of KDM4E was found to demethylate $\mathrm{H} 3 \mathrm{~K} 9 \mathrm{me} 3 / \mathrm{me} 2$ regulated by the availability of $\mathrm{O}_{2}$ in an in vitro assay (87).

The expression of $K D M 4 E / F$ in BC is still unknown. Further studies on these genes may unveil their potential role in $\mathrm{BC}$ and in other cancers. 


\section{KDM4 Inhibitors}

Depending on their mechanism of action, KDM4 inhibitors are divided into different classes: 2-OG cofactor mimics, metal cofactor disruptors, histone substrate-competitive inhibitors, and natural and peptide inhibitors (Figure 4) (88).

Cofactor mimics are metal-chelated inhibitors that competitively bind Fe(II) molecules of the catalytic site of KDM4 members, blocking their enzymatic activity. Cancer cells are able to reprogram their metabolism to support the increased energy demand required for cell survival and rapid proliferation. Metabolic disruption can alter KDM4 activity by modifying the availability of the required cofactor, 2-OG. Therefore, the intermediates of the tricarboxylic acid (TCA) cycle can inhibit KDM activity. The first identified KDM4 inhibitors were the natural molecules fumarate and succinate, which act as competitive antagonists for 2-OG (89).

Among 2-OG analogs, the oxalic acid-derivative $\mathrm{N}$-oxalylglycine (NOG: $\left.\mathrm{IC}_{50}=78 \mu \mathrm{M}\right)$, pyridine dicarboxylic acid $\left(\mathrm{PCA}: \mathrm{IC}_{50}=\right.$ $1.4 \mu \mathrm{M})$, and 8-hydroxyquinoline (8-HQ: $\left.\mathrm{IC}_{50}=0.6 \mu \mathrm{M}\right)$ showed antiproliferative activity (42).

The hydroxamate-based 2-OG analog NCDM-32B was identified as a good inhibitor of KDM4 subfamily members, and its therapeutic potential was investigated in basal-like $\mathrm{BC}$ (61). In enzymatic assays, NCDM-32B displayed $\mathrm{IC}_{50}$ values of $3.0 \mu \mathrm{M}$ for KDM4A and $1.0 \mu \mathrm{M}$ for KDM4C. Treatment with NCDM-32B in BC cell lines induced a global increase in $\mathrm{H} 3 \mathrm{~K} 9 \mathrm{me} 3 / \mathrm{me} 2$ marks, and microarray Gene Ontology analysis of differentially expressed genes revealed pathways that control cell proliferation, growth, DNA replication, and DNA repair.
Of note, the compound suppressed the expression of oncogenes, such as the MET proto-oncogene, as well as genes involved in cell cycle regulation including $C D C 26$ and $C D K 6$. These data suggest that NCDM-32B may be a regulator of different cell growth and transformation pathways activated in BC (61).

The orally available KDM4 inhibitor QC6352 has an $\mathrm{IC}_{50}$ value of $0.104 \mu \mathrm{M}$ for KDM4A, $0.056 \mu \mathrm{M}$ for KDM4B, and 0.035 $\mu \mathrm{M}$ for KDM4C (90). This molecule showed a strong capability to inhibit proliferation, sphere formation, and xenograft tumor formation of BC stem-like cells derived from tissue of TNBC patients after neoadjuvant chemotherapy. Via $\mathrm{H} 3 \mathrm{~K} 9 \mathrm{me} 3$ induction, QC6352 inhibited expression of epidermal growth factor receptor, a pivotal gene in therapy resistance mechanisms in TNBC (91).

A very recent study characterized TACH101 as a first-in-class pan inhibitor of KDM4s, with promising pharmacological applicability. Surprisingly, the compound displayed potent inhibitory activity on four KDM4 isoforms (A-D) with $\mathrm{IC}_{50}$ values below $0.100 \mu \mathrm{M}$. Furthermore, it increased H3K36me3 levels and induced apoptosis in human esophageal cancer, $\mathrm{TNBC}$, and colorectal cancer cell lines. In vivo, TACH101 showed $100 \%$ tumor growth inhibition in BC xenograft models, reducing tumor-initiating cell frequencies by 4.4 -fold, and exhibited good oral availability. However, further preclinical studies are required to drive progression of the compound to clinical trials (92).

Another interesting study reported that KDM4 inhibitors such as A1 (CGC00247751), B3 (NCGC00244536), and I9 (NCGC00247743) repress the transcriptional activity of AR

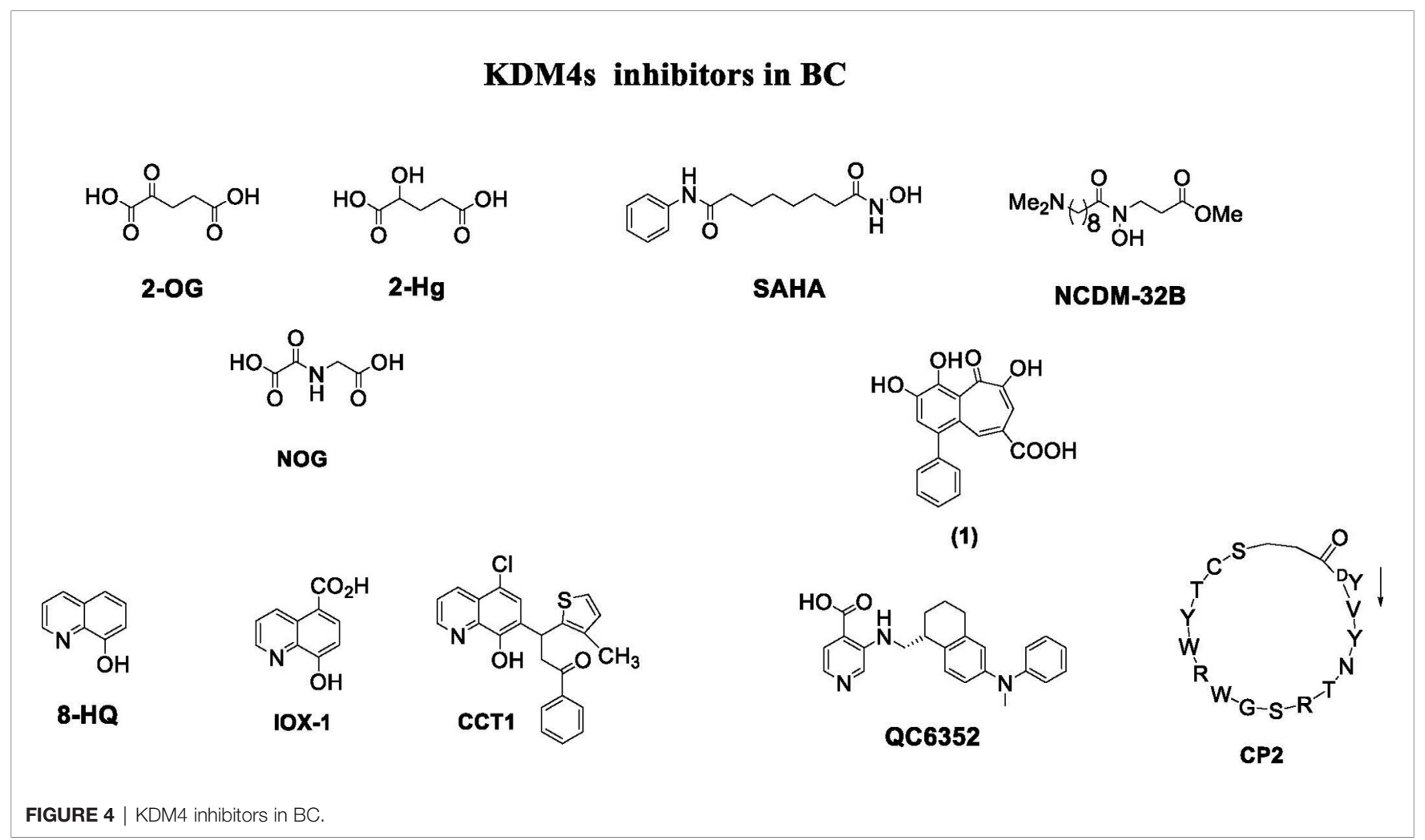


and $\mathrm{B}-\mathrm{MYB}$, regulating genes such as $P L K 1$, involved in cell cycle progression. Interestingly, the compound B3 showed antiproliferative effects in BC cell lines. Findings from this study suggest that the inhibitor specifically targets KDM4B in late S-phase due to activation of $P L K 1$ transcription via B-MYB, justifying the development of this KDM4B inhibitor for $\mathrm{AR}^{+}$ prostate cancer and opening up the possibility for new treatments in the $\mathrm{AR}^{+}$subgroup of $\mathrm{BC}$ (93).

Other selective KDM family inhibitors are also described as anticancer agents in BC. Many reports indicate that KDM5 maintains tumor-initiating cells and promotes the development of drug tolerance (94). A selective inhibitor of KDM5B, KDOAM-21, significantly increased global levels of H3K4me3 in MCF-7 and TNBC cells. The compound also inhibited the growth of MCF-7 cells at $5 \mu \mathrm{M}$ in colony-formation experiments (95). In another study, YUKA1, a small molecule inhibitor of KDM5A, displayed the ability to prevent drug tolerance in HER2 ${ }^{+}$BC cells treated with trastuzumab (96).

\section{Natural Inhibitors}

Quercetin (WO2007104314) is a natural flavonoid that was found to inhibit $\mathrm{KDM} 4 \mathrm{C}$ in demethylation assays and to modify $\mathrm{H} 3 \mathrm{~K} 9 \mathrm{me} 3$ demethylation status in esophageal carcinoma and bone osteosarcoma cells. A hydroxamate analog (JP2011168581) showed selective inhibition of KDM4A/C (88). Methylstat (US20130137720) is a methyl ester analog inhibiting KDM4C that increases hypermethylation levels of $\mathrm{H} 3 \mathrm{~K} 9 \mathrm{me} 3$ and $\mathrm{H} 3 \mathrm{~K} 36 \mathrm{me} 3$ in a concentration-dependent manner, blocking the growth of MCF-7 cells (97).

Curcumin derivatives show good inhibition of KMD4s at cellular level. For example, efficient histone demethylation was observed by FLLL compounds. Notably, FLLL- 8 and FLLL-24 displayed inhibitory activity against KDM4C, while FLLL-60 showed inhibition of KMD4A/D (98). Recently, a new compound synthesized from the natural product purpurogallin was reported to be a KDM4 inhibitor. This compound, called 9bf, exhibited a potent inhibitory activity on KDM4A and antiproliferative activity in many solid cancer cells (99).

\section{Peptide Inhibitors}

In 2014, the first peptide-based KDM4 inhibitors displaying major selectivity and minor off-target effects were described (100). Two cyclic peptides were identified and both were active against KDM4C. Interestingly, this study proposed a novel approach to developing selective KDM4 inhibitors, regardless of the substrate and cofactor used (100).

An in vitro screening of a cyclic peptide library identified selective substrate-competitive inhibitors of KDM4s, showing alteration of $\mathrm{H} 3 \mathrm{~K} 9 \mathrm{me} 3$ levels and inhibition of cell proliferation. The cyclic peptide $\mathrm{CP} 2$ showed potent $\mathrm{IC}_{50}$ values $\left(\mathrm{IC}_{50}=0.42 /\right.$ $0.33 / 0.39 \mu \mathrm{M}$ against $\mathrm{KDM} 4 \mathrm{~A} / \mathrm{B} / \mathrm{C}$, respectively) and exceptional intra-subfamily selectivity. The compound displayed high potency against $\mathrm{KDM} 4 \mathrm{~A} / \mathrm{B} / \mathrm{C}$ but was much less active against $\mathrm{KDM} 4 \mathrm{D}\left(\mathrm{IC}_{50}=6.2 \mu \mathrm{M}\right)$ and $\mathrm{KDM} 4 \mathrm{E}\left(\mathrm{IC}_{50}\right.$ $=9.2 \mu \mathrm{M})(101)$. Although further studies are needed to evaluate stability, cell permeability, and subcellular localization, this approach may lead to the discovery and characterization of potent peptide inhibitors of KDM4 for the treatment of $\mathrm{BC}$ and other cancers. Because the functions of non-catalytic domains of KDM4 subfamily members such as PHD and Tudor domains are still unknown, the development of KDM4 inhibitors against non-catalytic domains remains challenging.

\section{Dual and Other Inhibitors}

Since epigenetic machinery such as DNA methylation and histone modifications often work in parallel, the use of single agents in combination has recently drastically increased as this approach enhances their efficacy (102). Such a drug combination approach has also been exploited toward non-epigenetic targets (103). For example, combinations of HDAC-HSP90 inhibitors (104), HDAC-DNMT inhibitors (105), HDAC-KDM1 inhibitors (106), HDAC-BET protein inhibitors (107, 108), HDAC-EZH2 inhibitors (109), and HDAC-PI3K inhibitors (110) showed good efficacy in different cancer cells.

By way of an example, the dual KDM inhibitor MC3324 showed inhibition of KDM1 and KDM6A with a consequent increase in $\mathrm{H} 3 \mathrm{~K} 4 \mathrm{me} 2$ and $\mathrm{H} 3 \mathrm{~K} 24 \mathrm{me} 3$ levels and induction of apoptosis in hormone-responsive MCF-7 cells. Downregulation of $\mathrm{ER} \alpha$ was observed at both transcriptional and translational level, indicating that the compound affects the transcription of genes regulating cell proliferation, hormonal response, and apoptosis. Interestingly, MC3324 reduced cell proliferation in ex vivo BC models and showed absence of toxicity and good oral efficacy in chicken embryo and mouse xenograft models. Thus, the simultaneous inhibition of multiple targets could be beneficial in BC (111).

Combining different drugs could be a feasible strategy to target multiple oncogenic pathways (112-114). Currently, many two-in-one drug approaches are being investigated in clinical trials for various cancers. The well-known HDAC inhibitor vorinostat (SAHA) in combination with tamoxifen (NCT00365599), and carboplatin and nab-paclitaxel (NCT00616967) is at different stages of clinical trials. In another trial, entinostat (MS-275) in combination with immunotherapy and monoclonal antibodies (nivolumab, ipilimumab) is under evaluation in patients with metastatic BC and HER2- BC (NCT02453620). The synergy between HDAC inhibitors and anti-HER2 therapy with trastuzumab showed promising results (NCT00258349), but the adverse effects of trastuzumab resistance need to be further evaluated. In sum, in order to develop and optimize the effective use of epidrugs alone or in combination, there is an urgent need to identify new epigenetic targets that will pave the way for new cancer treatments.

In recent years, epigenetic studies combined with advanced computational methods have brought substantial advancements in drug discovery. A recent cutting-edge technology known as "epi-informatics" has been exploited to create a plethora of targeted compounds that may eventually lead to the discovery of new drugs. Computer-aided drug design could be used to explore and identify much needed selective KDM4 inhibitors for BC (115). 


\section{DISCUSSION}

The role of KDM4s in cancer has been extensively studied, and promising targets for BC therapy have been proposed. Through demethylation of $\mathrm{H} 3 \mathrm{~K} 9$ and $\mathrm{H} 3 \mathrm{~K} 36, \mathrm{KDM} 4 \mathrm{~s}$ regulate chromatin structure and gene expression in numerous cancer types. Notably, overexpression of KDM4 subfamily members promotes cancer cell proliferation, invasion, and migration, DNA damage, tumor angiogenesis, and metastasis. Although some epigenetic mechanisms and functions of KDM4 proteins associated with carcinogenesis remain unclear, a growing body of evidence indicates that KDM4 inhibitors are good candidates as anticancer drugs for various malignancies, including BC. To date, however, reported inhibitors do not have a sufficient level of enzyme specificity and are not commercially available for the treatment of any cancer types. The specific role of KDM4s and their mechanism of action in BC is less well known. Another challenging task is to explore new compounds against KDM4 activity through computational screening, which may identify more specific KDM4 inhibitors. Further studies could drive the future development of potent and selective targets for specific $\mathrm{KDM} 4 \mathrm{~s}$ in BC.

To improve overall healthcare outcomes in $\mathrm{BC}$, a substantial endeavor aimed at reducing mortality and increasing survival in patients is needed. Several studies have investigated the crucial role of KDM4 subfamily members in different cancers, and KDM4 targeting has been revealed as a promising strategy to inhibit BC development. However, no KDM4 modulators have as yet been approved for clinical use. Targeting these molecules has thus been attracting considerable interest among the scientific community $(62,88)$. The development of KDM4 inhibitors is still in its premature stage, with a limited number of scientific publications and patents. Although the development of potent and selective KDM4 inhibitors for BC is a complicated process, efforts in a number of different directions might be of help: i) The functions of KDM4E/F are still unclear, and more extensive investigations into these two enzymes may open up new avenues in cancer research. In addition, $\mathrm{KDM} 4 \mathrm{~A} / \mathrm{B} / \mathrm{C}$ share the same substrates, further complicating the development of selective inhibitors for KDM4 subtypes. Structural studies could help better define the catalytic pockets of these enzymes for more precise targeting $(116,117)$; ii) Specific gene expression patterns/ programs controlling KDM4 activity are poorly studied and need to be further explored; iii) Findings related to KDM4 inhibitors usually derive from in vitro or cell-based assays, with a lower amount of in vivo data being reported. Characterizing their in vivo activity might provide greater insights useful for more potent drug development; iv) The activity of KDM4s in regulating DNA damage, non-histone proteins, and other posttranslational modifications is still unclear. New research directed at understanding these mechanisms may lead to the identification of novel molecules with higher selectivity: v) Due to their structural similarities and the presence of a JmjC domain in all isoforms of KDM4, engineering KDM4 inhibitors with isoform specificity is challenging. However, elucidating the distinct physiological function of each KDM4 enzymes in cancer is necessary.

Moving from a single- to a multi-KDM4s target therapeutic approach may be a useful strategy to improve $\mathrm{BC}$ treatment. Specifically, hybrid scaffolds coupling two individually well-known KDM4i compounds in a single unit (dual compound) could be a valid option to simultaneously target different KDM4 isoforms. As reported, the molecule MC3324 was more effective in blocking cell proliferation, targeting ER, and inducing cell death of BC cells, compared to its constituent moieties and other known inhibitors used alone or in combination. Alternatively, dual compounds could also be used to directly target KDM4 isoforms and their coregulators in a highly specific manner. Hybrid scaffolds bridging binders of KDM4 isoform domains could be used to target a dual compound to KDM4 isoforms, thus overcoming the lack of specificity towards isoforms. However, the complexity and vulnerability of epigenetic regulation limits the use of epigenetic molecules to specific treatment contexts, which may contribute to poor therapeutic outcome. Studies into combinatorial epigenetic therapy have recently paved the way toward exploring new effective therapeutic strategy in cancer. For instance, polyclonal tumors are characterized by the presence of multiple coactive deregulated pathways, and in these tumors epigenetic alterations are favoring, permissive, or secondary events. In this scenario, testing novel targeted treatments in a single-agent approach may thus be problematic and may underestimate their effectiveness. Combining epigenetic drugs with conventional protocols, both targeted and immune therapies, may therefore represent a successful anticancer approach.

Exploiting single-cell omics approaches could capture cancer cell heterogeneity and provide a better understanding of the involvement of different KDM4s in the sequential stages of breast transformation at both bulk and single-cell level. This approach may ensure a more accurate patient stratification and unravel the role of each KDM4 in $\mathrm{BC}$ transformation, allowing evaluation of the efficacy of targeted selective modulators and opening the way toward personalized medicine in $\mathrm{BC}$ driven by specific KDM4 aberrations.

Unlike genetic events, epigenetic changes are reversible and because of this inherent plasticity, epigenome-targeted therapy has emerged as a potential strategy for the treatment of cancer. The results of investigational and approved epigenetic therapies in other clinical contexts have proven that this approach can be effective. KDM4s have been found to control many aspects of BC, including cancer initiation and progression. Additionally, traditional BC treatments fail in targeting therapy-resistant cancer stem cells strongly characterized by alteration of epiregulators. Thus, considering that KDM4s are epigenetic regulators with overlapping functions in controlling gene expression of crucial signaling pathways, KDM4s inhibition reflects their target potential for BC therapy. Targeting these histone demethylases will pave the way toward improving the treatment of $\mathrm{BC}$ patients. 


\section{AUTHOR CONTRIBUTIONS}

Conceptualization and writing BV, NDG, and GC. Supervision $\mathrm{AN}$ and LA. All authors contributed to the article and approved the submitted version.

\section{FUNDING}

This work was supported by the Italian Association for Cancer Research (AIRC-17217), the Campania Regional Government "Lotta

\section{REFERENCES}

1. Lee EY, Muller WJ. Oncogenes and Tumor Suppressor Genes. Cold Spring Harb Perspect Biol (2010) 2(10):a003236. doi: 10.1101/cshperspect.a003236

2. Torgovnick A, Schumacher B. DNA Repair Mechanisms in Cancer Development and Therapy. Front Genet (2015) 6:157. doi: 10.3389/ fgene.2015.00157

3. Loibl S, Poortmans P, Morrow M, Denkert C, Curigliano G. Breast Cancer. Lancet (2021) 397(10286):1750-69. doi: 10.1016/s0140-6736(20)32381-3

4. Tomczak K, Czerwińska P, Wiznerowicz M. Review The Cancer Genome Atlas (TCGA): An Immeasurable Source of Knowledge. Współczesna Onkol (2015) 1A:68-77. doi: 10.5114/wo.2014.47136

5. Harbeck N, Penault-Llorca F, Cortes J, Gnant M, Houssami N, Poortmans P, et al. Breast Cancer. Nat Rev Dis Primers (2019) 5(1):66. doi: 10.1038/ s41572-019-0111-2

6. Smigiel JM, Taylor SE, Bryson BL, Tamagno I, Polak K, Jackson MW. Cellular Plasticity and Metastasis in Breast Cancer: A Pre- and PostMalignant Problem. J Cancer Metastasis Treat (2019) 5:47. doi: 10.20517/ 2394-4722.2019.26

7. Garcia-Martinez L, Zhang Y, Nakata Y, Chan HL, Morey L. Epigenetic Mechanisms in Breast Cancer Therapy and Resistance. Nat Commun (2021) 12(1):1786. doi: 10.1038/s41467-021-22024-3

8. Diesch J, Zwick A, Garz AK, Palau A, Buschbeck M, Gotze KS. A ClinicalMolecular Update on Azanucleoside-Based Therapy for the Treatment of Hematologic Cancers. Clin Epigenet (2016) 8:71. doi: 10.1186/s13148-0160237-y

9. Ganesan A, Arimondo PB, Rots MG, Jeronimo C, Berdasco M. The Timeline of Epigenetic Drug Discovery: From Reality to Dreams. Clin Epigenet (2019) 11(1):174. doi: 10.1186/s13148-019-0776-0

10. Mosammaparast N, Shi Y. Reversal of Histone Methylation: Biochemical and Molecular Mechanisms of Histone Demethylases. Annu Rev Biochem (2010) 79:155-79. doi: 10.1146/annurev.biochem.78.070907.103946

11. Labbe RM, Holowatyj A, Yang ZQ. Histone Lysine Demethylase (KDM) Subfamily 4: Structures, Functions and Therapeutic Potential. Am J Trans Res (2013) 6(1):1-15.

12. Klose RJ, Kallin EM, Zhang Y. JmjC-Domain-Containing Proteins and Histone Demethylation. Nat Rev Genet (2006) 7(9):715-27. doi: 10.1038/ nrg1945

13. Slama P. Identification of Family Determining Residues in Jumonji-C Lysine Demethylases: A Sequence-Based, Family Wide Classification. Proteins (2016) 84(3):397-407. doi: 10.1002/prot.24986

14. Tavazoie SF, Alarcon C, Oskarsson T, Padua D, Wang Q, Bos PD, et al. Endogenous Human microRNAs That Suppress Breast Cancer Metastasis. Nature (2008) 451(7175):147-52. doi: 10.1038/nature06487

15. Paolicchi E, Crea F, Farrar WL, Green JE, Danesi R. Histone Lysine Demethylases in Breast Cancer. Crit Rev Oncol Hematol (2013) 86(2):97103. doi: 10.1016/j.critrevonc.2012.11.008

16. Liu X, Wang Y, Gao Y, Su J, Zhang J, Xing X, et al. H3K9 Demethylase KDM4E Is an Epigenetic Regulator for Bovine Embryonic Development and a Defective Factor for Nuclear Reprogramming. Development (2018) 145(4): dev158261. doi: 10.1242/dev.158261

17. Berry WL, Janknecht R. KDM4/JMJD2 Histone Demethylases: Epigenetic Regulators in Cancer Cells. Cancer Res (2013) 73(10):2936-42. doi: 10.1158/ 0008-5472.CAN-12-4300 alle Patologie Oncologiche" iCURE (CUP B21C17000030007), MIUR Proof Of Concept (POC01_00043), VALERE: Vanvitelli per la Ricerca Program: AdipCare (ID263) and EPInhibitDRUGre (CUP B66J20000680005).

\section{ACKNOWLEDGMENTS}

We thank C. Fisher for English language editing.

18. Huang F, Chandrasekharan MB, Chen YC, Bhaskara S, Hiebert SW, Sun ZW. The JmjN Domain of Jhd2 Is Important for its Protein Stability, and the Plant Homeodomain (PHD) Finger Mediates its Chromatin Association Independent of H3K4 Methylation. J Biol Chem (2010) 285(32):24548-61. doi: $10.1074 /$ jbc.M110.117333

19. Ozboyaci M, Gursoy A, Erman B, Keskin O. Molecular Recognition of H3/ H4 Histone Tails by the Tudor Domains of JMJD2A: A Comparative Molecular Dynamics Simulations Study. PloS One (2011) 6(3):e14765. doi: 10.1371/journal.pone.0014765

20. Black JC, Van Rechem C, Whetstine JR. Histone Lysine Methylation Dynamics: Establishment, Regulation, and Biological Impact. Mol Cell (2012) 48(4):491-507. doi: 10.1016/j.molcel.2012.11.006

21. Tan MK, Lim HJ, Harper JW. SCF(FBXO22) Regulates Histone H3 Lysine 9 and 36 Methylation Levels by Targeting Histone Demethylase KDM4A for Ubiquitin-Mediated Proteasomal Degradation. Mol Cell Biol (2011) 31 (18):3687-99. doi: 10.1128/MCB.05746-11

22. Skarnes WC, Rosen B, West AP, Koutsourakis M, Bushell W, Iyer V, et al. A Conditional Knockout Resource for the Genome-Wide Study of Mouse Gene Function. Nature (2011) 474(7351):337-42. doi: 10.1038/nature10163

23. Wan M, Liang J, Xiong Y, Shi F, Zhang Y, Lu W, et al. The Trithorax Group Protein Ash21 Is Essential for Pluripotency and Maintaining Open Chromatin in Embryonic Stem Cells. J Biol Chem (2013) 288(7):5039-48. doi: 10.1074/jbc.M112.424515

24. Tsurumi A, Xue S, Zhang L, Li J, Li WX. Genome-Wide Kdm4 Histone Demethylase Transcriptional Regulation in Drosophila. Mol Genet Genomics (2019) 294(5):1107-21. doi: 10.1007/s00438-019-01561-z

25. Ferrand J, Rondinelli B, Polo SE. Histone Variants: Guardians of Genome Integrity. Cells (2020) 9(11):2424. doi: 10.3390/cells9112424

26. Das PP, Shao Z, Beyaz S, Apostolou E, Pinello L, De Los Angeles A, et al. Distinct and Combinatorial Functions of Jmjd2b/Kdm4b and Jmjd2c/ $\mathrm{Kdm} 4 \mathrm{c}$ in Mouse Embryonic Stem Cell Identity. Mol Cell (2014) 53 (1):32-48. doi: 10.1016/j.molcel.2013.11.011

27. Wang J, Zhang M, Zhang Y, Kou Z, Han Z, Chen DY, et al. The Histone Demethylase JMJD2C Is Stage-Specifically Expressed in Preimplantation Mouse Embryos and Is Required for Embryonic Development. Biol Reprod (2010) 82(1):105-11. doi: 10.1095/biolreprod.109.078055

28. Ye L, Fan Z, Yu B, Chang J, Al Hezaimi K, Zhou X, et al. Histone Demethylases KDM4B and KDM6B Promotes Osteogenic Differentiation of Human MSCs. Cell Stem Cell (2012) 11(1):50-61. doi: 10.1016/ j.stem.2012.04.009

29. Scarborough GA, Hennessey JP Jr. Identification of the Major Cytoplasmic Regions of the Neurospora Crassa Plasma Membrane H(+)-ATPase Using Protein Chemical Techniques. J Biol Chem (1990) 265(27):16145-9. doi 10.1016/S0021-9258(17)46200-4

30. Agger K, Nishimura K, Miyagi S, Messling JE, Rasmussen KD, Helin K. The KDM4/JMJD2 Histone Demethylases Are Required for Hematopoietic Stem Cell Maintenance. Blood (2019) 134(14):1154-8. doi: 10.1182/blood. 2019000855

31. Verrier L, Escaffit F, Chailleux C, Trouche D, Vandromme M. A New Isoform of the Histone Demethylase JMJD2A/KDM4A Is Required for Skeletal Muscle Differentiation. PloS Genet (2011) 7(6):e1001390. doi: 10.1371/journal.pgen.1001390

32. Fujiwara K, Fujita Y, Kasai A, Onaka Y, Hashimoto H, Okada H, et al. Deletion of JMJD2B in Neurons Leads to Defective Spine Maturation, 
Hyperactive Behavior and Memory Deficits in Mouse. Trans Psychiatry (2016) 6:e766. doi: 10.1038/tp.2016.31

33. Choi JY, Yoon SS, Kim SE, Ahn Jo S. KDM4B Histone Demethylase and G9a Regulate Expression of Vascular Adhesion Proteins in Cerebral Microvessels. Sci Rep (2017) 7:45005. doi: 10.1038/srep45005

34. Sankar A, Kooistra SM, Gonzalez JM, Ohlsson C, Poutanen M, Helin K. Maternal Expression of the Histone Demethylase Kdm4a Is Crucial for PreImplantation Development. Development (2017) 144(18):3264-77. doi: $10.1242 /$ dev.155473

35. Iwamori N, Zhao M, Meistrich ML, Matzuk MM. The Testis-Enriched Histone Demethylase, KDM4D, Regulates Methylation of Histone H3 Lysine 9 During Spermatogenesis in the Mouse But Is Dispensable for Fertility. Biol Reprod (2011) 84(6):1225-34. doi: 10.1095/biolreprod.110.088955

36. Khoury-Haddad H, Nadar-Ponniah PT, Awwad S, Ayoub N. The Emerging Role of Lysine Demethylases in DNA Damage Response: Dissecting the Recruitment Mode of KDM4D/JMJD2D to DNA Damage Sites. Cell Cycle (2015) 14(7):950-8. doi: 10.1080/15384101.2015.1014147

37. Kawazu M, Saso K, Tong KI, McQuire T, Goto K, Son DO, et al. Histone Demethylase JMJD2B Functions as a Co-Factor of Estrogen Receptor in Breast Cancer Proliferation and Mammary Gland Development. PloS One (2011) 6(3):e17830. doi: 10.1371/journal.pone.0017830

38. Couse JF, Yates MM, Deroo BJ, Korach KS. Estrogen Receptor-Beta Is Critical to Granulosa Cell Differentiation and the Ovulatory Response to Gonadotropins. Endocrinology (2005) 146(8):3247-62. doi: 10.1210/ en.2005-0213

39. Emmen JM, Couse JF, Elmore SA, Yates MM, Kissling GE, Korach KS. In Vitro Growth and Ovulation of Follicles From Ovaries of Estrogen Receptor (ER) \{alpha\} and ER\{beta\} Null Mice Indicate a Role for ER $\{$ beta $\}$ in Follicular Maturation. Endocrinology (2005) 146(6):2817-26. doi: 10.1210/ en.2004-1108

40. Gaughan L, Stockley J, Coffey K, O’Neill D, Jones DL, Wade M, et al. KDM4B Is a Master Regulator of the Estrogen Receptor Signalling Cascade. Nucleic Acids Res (2013) 41(14):6892-904. doi: 10.1093/nar/gkt469

41. Zack TI, Schumacher SE, Carter SL, Cherniack AD, Saksena G, Tabak B, et al. Pan-Cancer Patterns of Somatic Copy Number Alteration. Nat Genet (2013) 45(10):1134-40. doi: 10.1038/ng.2760

42. Lin H, Li Q, Li Q, Zhu J, Gu K, Jiang X, et al. Small Molecule KDM4s Inhibitors as Anti-Cancer Agents. J Enzyme Inhib Med Chem (2018) 33 (1):777-93. doi: 10.1080/14756366.2018.1455676

43. Black JC, Manning AL, Van Rechem C, Kim J, Ladd B, Cho J, et al. KDM4A Lysine Demethylase Induces Site-Specific Copy Gain and Rereplication of Regions Amplified in Tumors. Cell (2013) 154(3):541-55. doi: 10.1016/ j.cell.2013.06.051

44. Wissmann M, Yin N, Muller JM, Greschik H, Fodor BD, Jenuwein T, et al. Cooperative Demethylation by JMJD2C and LSD1 Promotes Androgen Receptor-Dependent Gene Expression. Nat Cell Biol (2007) 9(3):347-53. doi: $10.1038 /$ ncb 1546

45. Shin S, Janknecht R. Activation of Androgen Receptor by Histone Demethylases JMJD2A and JMJD2D. Biochem Biophys Res Commun (2007) 359(3):742-6. doi: 10.1016/j.bbrc.2007.05.179

46. Xu W, Jiang K, Shen M, Chen Y, Huang HY. Jumonji Domain Containing 2A Predicts Prognosis and Regulates Cell Growth in Lung Cancer Depending on miR-150. Oncol Rep (2016) 35(1):352-8. doi: 10.3892/or.2015.4349

47. Kveiborg M, Albrechtsen R, Couchman JR, Wewer UM. Cellular Roles of ADAM12 in Health and Disease. Int J Biochem Cell Biol (2008) 40(9):1685702. doi: 10.1016/j.biocel.2008.01.025

48. Narayan S, Moyes B, Wolff S. Family Characteristics of Autistic Children: A Further Report. J Autism Dev Disord (1990) 20(4):523-35. doi: 10.1007/ BF02216057

49. Li A, King J, Moro A, Sugi MD, Dawson DW, Kaplan J, et al. Overexpression of CXCL5 Is Associated With Poor Survival in Patients With Pancreatic Cancer. Am J Pathol (2011) 178(3):1340-9. doi: 10.1016/j.ajpath.2010.11.058

50. Hofmann JJ, Luisa Iruela-Arispe M. Notch Expression Patterns in the Retina: An Eye on Receptor-Ligand Distribution During Angiogenesis. Gene Expr Patterns (2007) 7(4):461-70. doi: 10.1016/j.modgep.2006.11.002

51. Soini Y, Kosma VM, Pirinen R. KDM4A, KDM4B and KDM4C in nonSmall Cell Lung Cancer. Int J Clin Exp Pathol (2015) 8(10):12922-8.
52. Li X, Dong S. Histone Demethylase JMJD2B and JMJD2C Induce Fibroblast Growth Factor 2: Mediated Tumorigenesis of Osteosarcoma. Med Oncol (2015) 32(3):53. doi: 10.1007/s12032-015-0503-4

53. Zhu Y, van Essen D, Saccani S. Cell-Type-Specific Control of Enhancer Activity by H3K9 Trimethylation. Mol Cell (2012) 46(4):408-23. doi: 10.1016/j.molcel.2012.05.011

54. Kim TD, Oh S, Shin S, Janknecht R. Regulation of Tumor Suppressor P53 and HCT116 Cell Physiology by Histone Demethylase JMJD2D/KDM4D. PloS One (2012) 7(4):e34618. doi: 10.1371/journal.pone.0034618

55. Mallette FA, Richard S. JMJD2A Promotes Cellular Transformation by Blocking Cellular Senescence Through Transcriptional Repression of the Tumor Suppressor CHD5. Cell Rep (2012) 2(5):1233-43. doi: 10.1016/ j.celrep.2012.09.033

56. Wilson C, Qiu L, Hong Y, Karnik T, Tadros G, Mau B, et al. The Histone Demethylase KDM4B Regulates Peritoneal Seeding of Ovarian Cancer. Oncogene (2017) 36(18):2565-76. doi: 10.1038/onc.2016.412

57. Hu F, Li H, Liu L, Xu F, Lai S, Luo X, et al. Histone Demethylase KDM4D Promotes Gastrointestinal Stromal Tumor Progression Through HIFlbeta/ VEGFA Signalling. Mol Cancer (2018) 17(1):107. doi: 10.1186/s12943-0180861-6

58. Yang J, Jubb AM, Pike L, Buffa FM, Turley H, Baban D, et al. The Histone Demethylase JMJD2B Is Regulated by Estrogen Receptor Alpha and Hypoxia, and Is a Key Mediator of Estrogen Induced Growth. Cancer Res (2010) 70(16):6456-66. doi: 10.1158/0008-5472.CAN-10-0413

59. Fu L, Chen L, Yang J, Ye T, Chen Y, Fang J. HIF-1alpha-Induced Histone Demethylase JMJD2B Contributes to the Malignant Phenotype of Colorectal Cancer Cells via an Epigenetic Mechanism. Carcinogenesis (2012) 33 (9):1664-73. doi: 10.1093/carcin/bgs217

60. Beyer S, Kristensen MM, Jensen KS, Johansen JV, Staller P. The Histone Demethylases JMJD1A and JMJD2B Are Transcriptional Targets of Hypoxia-Inducible Factor HIF. J Biol Chem (2008) 283(52):36542-52. doi: $10.1074 /$ jbc.M804578200

61. Ye Q, Holowatyj A, Wu J, Liu H, Zhang L, Suzuki T, et al. Genetic Alterations of KDM4 Subfamily and Therapeutic Effect of Novel Demethylase Inhibitor in Breast Cancer. Am J Cancer Res (2015) 5 (4):1519-30

62. Kim TD, Shin S, Berry WL, Oh S, Janknecht R. The JMJD2A Demethylase Regulates Apoptosis and Proliferation in Colon Cancer Cells. J Cell Biochem (2012) 113(4):1368-76. doi: 10.1002/jcb.24009

63. Zhang D, Yoon HG, Wong J. JMJD2A Is a Novel N-CoR-Interacting Protein and Is Involved in Repression of the Human Transcription Factor Achaete Scute-Like Homologue 2 (ASCL2/Hash2). Mol Cell Biol (2005) 25(15):640414. doi: 10.1128/MCB.25.15.6404-6414.2005

64. Patani N, Jiang WG, Newbold RF, Mokbel K. Histone-Modifier Gene Expression Profiles Are Associated With Pathological and Clinical Outcomes in Human Breast Cancer. Anticancer Res (2011) 31(12):4115-25.

65. Berry WL, Shin S, Lightfoot SA, Janknecht R. Oncogenic Features of the JMJD2A Histone Demethylase in Breast Cancer. Int J Oncol (2012) 41 (5):1701-6. doi: 10.3892/ijo.2012.1618

66. Li LL, Xue AM, Li BX, Shen YW, Li YH, Luo CL, et al. JMJD2A Contributes to Breast Cancer Progression Through Transcriptional Repression of the Tumor Suppressor ARHI. Breast Cancer Res (2014) 16(3):R56. doi: 10.1186/ bcr3667

67. Li L, Gao P, Li Y, Shen Y, Xie J, Sun D, et al. JMJD2A-Dependent Silencing of Sp1 in Advanced Breast Cancer Promotes Metastasis by Downregulation of DIRAS3. Breast Cancer Res Treat (2014) 147(3):487-500. doi: 10.1007/ s10549-014-3083-7

68. Li BX, Luo CL, Li H, Yang P, Zhang MC, Xu HM, et al. Effects of siRNAMediated Knockdown of Jumonji Domain Containing 2A on Proliferation, Migration and Invasion of the Human Breast Cancer Cell Line MCF-7. Exp Ther Med (2012) 4(4):755-61. doi: 10.3892/etm.2012.662

69. Li BX, Zhang MC, Luo CL, Yang P, Li H, Xu HM, et al. Effects of RNA Interference-Mediated Gene Silencing of JMJD2A on Human Breast Cancer Cell Line MDA-MB-231 In Vitro. J Exp Clin Cancer Res (2011) 30:90. doi: 10.1186/1756-9966-30-90

70. Wang J, Wang H, Wang LY, Cai D, Duan Z, Zhang Y, et al. Silencing the Epigenetic Silencer KDM4A for TRAIL and DR5 Simultaneous Induction 
and Antitumor Therapy. Cell Death Differ (2016) 23(11):1886-96. doi: $10.1038 /$ cdd. 2016.92

71. Black JC, Zhang H, Kim J, Getz G, Whetstine JR. Regulation of Transient Site-Specific Copy Gain by MicroRNA. J Biol Chem (2016) 291(10):4862-71. doi: 10.1074/jbc.M115.711648

72. Guerra-Calderas L, Gonzalez-Barrios R, Patino CC, Alcaraz N, Salgado-Albarran M, de Leon DC, et al. CTCF-KDM4A Complex Correlates With Histone Modifications That Negatively Regulate CHD5 Gene Expression in Cancer Cell Lines. Oncotarget (2018) 9(24):17028-42. doi: 10.18632/oncotarget.24798

73. Levin M, Stark M, Assaraf YG. The JmjN Domain as a Dimerization Interface and a Targeted Inhibitor of KDM4 Demethylase Activity. Oncotarget (2018) 9(24):16861-82. doi: 10.18632/oncotarget.24717

74. Shi L, Sun L, Li Q, Liang J, Yu W, Yi X, et al. Histone Demethylase JMJD2B Coordinates H3K4/H3K9 Methylation and Promotes Hormonally Responsive Breast Carcinogenesis. Proc Natl Acad Sci USA (2011) 108 (18):7541-6. doi: 10.1073/pnas.1017374108

75. Jones D, Wilson L, Thomas H, Gaughan L, Wade MA. The Histone Demethylase Enzymes KDM3A and KDM4B Co-Operatively Regulate Chromatin Transactions of the Estrogen Receptor in Breast Cancer. Cancers (2019) 11(8):1122. doi: 10.3390/cancers 11081122

76. Xiang Y, Yan K, Zheng Q, Ke H, Cheng J, Xiong W, et al. Histone Demethylase KDM4B Promotes DNA Damage by Activating Long Interspersed Nuclear Element-1. Cancer Res (2019) 79(1):86-98. doi: 10.1158/0008-5472.CAN-18-1310

77. Slee RB, Steiner CM, Herbert BS, Vance GH, Hickey RJ, Schwarz T, et al. Cancer-Associated Alteration of Pericentromeric Heterochromatin may Contribute to Chromosome Instability. Oncogene (2012) 31(27):3244-53. doi: 10.1038/onc.2011.502

78. Wang W, Oguz G, Lee PL, Bao Y, Wang P, Terp MG, et al. KDM4BRegulated Unfolded Protein Response as a Therapeutic Vulnerability in PTEN-Deficient Breast Cancer. J Exp Med (2018) 215(11):2833-49. doi: 10.1084/jem.20180439

79. Johmura Y, Maeda I, Suzuki N, Wu W, Goda A, Morita M, et al. Fbxo22Mediated KDM4B Degradation Determines Selective Estrogen Receptor Modulator Activity in Breast Cancer. J Clin Invest (2018) 128(12):560319. doi: $10.1172 / J C I 121679$

80. Liu G, Bollig-Fischer A, Kreike B, van de Vijver MJ, Abrams J, Ethier SP, et al. Genomic Amplification and Oncogenic Properties of the GASC1 Histone Demethylase Gene in Breast Cancer. Oncogene (2009) 28 (50):4491-500. doi: 10.1038/onc.2009.297

81. Hong Q, Yu S, Yang Y, Liu G, Shao Z. A Polymorphism in JMJD2C Alters the Cleavage by Caspase- 3 and the Prognosis of Human Breast Cancer. Oncotarget (2014) 5(13):4779-87. doi: 10.18632/oncotarget.2029

82. Berdel B, Nieminen K, Soini Y, Tengstrom M, Malinen M, Kosma VM, et al. Histone Demethylase GASC1-A Potential Prognostic and Predictive Marker in Invasive Breast Cancer. BMC Cancer (2012) 12:516. doi: 10.1186/1471-2407-12-516

83. Luo W, Chang R, Zhong J, Pandey A, Semenza GL. Histone Demethylase JMJD2C Is a Coactivator for Hypoxia-Inducible Factor 1 That Is Required for Breast Cancer Progression. Proc Natl Acad Sci USA (2012) 109(49): E3367-76. doi: 10.1073/pnas.1217394109

84. Garcia J, Lizcano F. KDM4C Activity Modulates Cell Proliferation and Chromosome Segregation in Triple-Negative Breast Cancer. Breast Cancer (2016) 10:169-75. doi: 10.4137/BCBCR.S40182

85. Walsh CA, Bolger JC, Byrne C, Cocchiglia S, Hao Y, Fagan A, et al. Global Gene Repression by the Steroid Receptor Coactivator SRC-1 Promotes Oncogenesis. Cancer Res (2014) 74(9):2533-44. doi: 10.1158/0008-5472.CAN-13-2133

86. Hillringhaus L, Yue WW, Rose NR, Ng SS, Gileadi C, Loenarz C, et al. Structural and Evolutionary Basis for the Dual Substrate Selectivity of Human KDM4 Histone Demethylase Family. J Biol Chem (2011) 286 (48):41616-25. doi: 10.1074/jbc.M111.283689

87. Sanchez-Fernandez EM, Tarhonskaya H, Al-Qahtani K, Hopkinson RJ, McCullagh JS, Schofield CJ, et al. Investigations on the Oxygen Dependence of a 2-Oxoglutarate Histone Demethylase. Biochem J (2013) 449(2):491-6. doi: 10.1042/BJ20121155

88. Chin YW, Han SY. KDM4 Histone Demethylase Inhibitors for Anti-Cancer Agents: A Patent Review. Expert Opin Ther Pat (2015) 25(2):135-44. doi: $10.1517 / 13543776.2014 .991310$
89. Smith EH, Janknecht R, Maher LJ3rd. Succinate Inhibition of AlphaKetoglutarate-Dependent Enzymes in a Yeast Model of Paraganglioma. Hum Mol Genet (2007) 16(24):3136-48. doi: 10.1093/hmg/ddm275

90. Chen YK, Bonaldi T, Cuomo A, Del Rosario JR, Hosfield DJ, Kanouni T, et al. Design of KDM4 Inhibitors With Antiproliferative Effects in Cancer Models. ACS Med Chem Lett (2017) 8(8):869-74. doi: 10.1021/ acsmedchemlett.7b00220

91. Metzger E, Stepputtis SS, Strietz J, Preca BT, Urban S, Willmann D, et al. KDM4 Inhibition Targets Breast Cancer Stem-Like Cells. Cancer Res (2017) 77(21):5900-12. doi: 10.1158/0008-5472.CAN-17-1754

92. Yoo S, Chandhasin C, Rosario JRD, Chen YK, Stafford J, Quake S, et al. Abstract 2128: TACH101, A First-in-Class Pan Inhibitor of KDM4 Histone Lysine Demethylases. Cancer Res (2021) 81(13 Supplement):2128. doi: 10.1158/1538-7445.am2021-2128

93. Duan L, Rai G, Roggero C, Zhang Q-J, Wei Q, Ma Shi H, et al. KDM4/JMJD2 Histone Demethylase Inhibitors Block Prostate Tumor Growth by Suppressing the Expression of AR and BMYB-Regulated Genes. Chem Biol (2015) 22(9):1185-96. doi: 10.1016/j.chembiol.2015.08.007

94. Rotili D, Mattevi A. At Long Last Potent and Selective KDM5 Inhibitors. Cell Chem Biol (2016) 23(7):749-51. doi: 10.1016/j.chembiol.2016.07.003

95. Hatch SB, Yapp C, Montenegro RC, Savitsky P, Gamble V, Tumber A, et al. Assessing Histone Demethylase Inhibitors in Cells: Lessons Learned. Epigenet Chromatin (2017) 10:9. doi: 10.1186/s13072-017-0116-6

96. Gale M, Sayegh J, Cao J, Norcia M, Gareiss P, Hoyer D, et al. ScreenIdentified Selective Inhibitor of Lysine Demethylase 5A Blocks Cancer Cell Growth and Drug Resistance. Oncotarget (2016) 7(26):39931-44. doi: 10.18632/oncotarget.9539

97. Luo X, Liu Y, Kubicek S, Myllyharju J, Tumber A, Ng S, et al. A Selective Inhibitor and Probe of the Cellular Functions of Jumonji C DomainContaining Histone Demethylases. J Am Chem Soc (2011) 133(24):9451-6. doi: $10.1021 / j a 201597 b$

98. Kim TD, Fuchs JR, Schwartz E, Abdelhamid D, Etter J, Berry WL, et al. ProGrowth Role of the JMJD2C Histone Demethylase in HCT-116 Colon Cancer Cells and Identification of Curcuminoids as JMJD2 Inhibitors. Am J Trans Res (2014) 6(3):236-47.

99. Souto JA, Sarno F, Nebbioso A, Papulino C, Alvarez R, Lombino J, et al. A New Family of Jumonji C Domain-Containing KDM Inhibitors Inspired by Natural Product Purpurogallin. Front Chem (2020) 8:312. doi: 10.3389/ fchem.2020.00312

100. Leurs U, Lohse B, Rand KD, Ming S, Riise ES, Cole PA, et al. Substrate- and Cofactor-Independent Inhibition of Histone Demethylase KDM4C. ACS Chem Biol (2014) 9(9):2131-8. doi: 10.1021/cb500374f

101. Kawamura A, Munzel M, Kojima T, Yapp C, Bhushan B, Goto Y, et al. Highly Selective Inhibition of Histone Demethylases by De Novo Macrocyclic Peptides. Nat Commun (2017) 8:14773. doi: 10.1038/ncomms14773

102. Majchrzak-Celinska A, Warych A, Szoszkiewicz M. Novel Approaches to Epigenetic Therapies: From Drug Combinations to Epigenetic Editing. Genes (2021) 12(2):208. doi: 10.3390/genes12020208

103. Nepali K, Liou JP. Recent Developments in Epigenetic Cancer Therapeutics: Clinical Advancement and Emerging Trends. J Biomed Sci (2021) 28(1):27. doi: 10.1186/s12929-021-00721-x

104. George P, Bali P, Annavarapu S, Scuto A, Fiskus W, Guo F, et al. Combination of the Histone Deacetylase Inhibitor LBH589 and the Hsp90 Inhibitor 17-AAG Is Highly Active Against Human CML-BC Cells and AML Cells With Activating Mutation of FLT-3. Blood (2005) 105(4):176876. doi: 10.1182/blood-2004-09-3413

105. Pathania R, Ramachandran S, Mariappan G, Thakur P, Shi H, Choi JH, et al. Combined Inhibition of DNMT and HDAC Blocks the Tumorigenicity of Cancer Stem-Like Cells and Attenuates Mammary Tumor Growth. Cancer Res (2016) 76(11):3224-35. doi: 10.1158/0008-5472.CAN-15-2249

106. Kalin JH, Wu M, Gomez AV, Song Y, Das J, Hayward D, et al. Targeting the CoREST Complex With Dual Histone Deacetylase and Demethylase Inhibitors. Nat Commun (2018) 9(1):53. doi: 10.1038/s41467-017-02242-4

107. Zhang X, Zegar T, Weiser T, Hamdan FH, Berger BT, Lucas R, et al. Characterization of a Dual BET/HDAC Inhibitor for Treatment of Pancreatic Ductal Adenocarcinoma. Int J Cancer (2020) 147(10):2847-61. doi: $10.1002 /$ ijc. 33137 
108. Romanelli A, Stazi G, Fioravanti R, Zwergel C, Di Bello E, Pomella S, et al. Design of First-In-Class Dual EZH2/HDAC Inhibitor: Biochemical Activity and Biological Evaluation in Cancer Cells. ACS Med Chem Lett (2020) 11 (5):977-83. doi: 10.1021/acsmedchemlett.0c00014

109. Lue JK, Prabhu SA, Liu Y, Gonzalez Y, Verma A, Mundi PS, et al. Precision Targeting With EZH2 and HDAC Inhibitors in Epigenetically Dysregulated Lymphomas. Clin Cancer Res (2019) 25(17):5271-83. doi: 10.1158/10780432.CCR-18-3989

110. Thakur A, Tawa GJ, Henderson MJ, Danchik C, Liu S, Shah P, et al. Design, Synthesis, and Biological Evaluation of Quinazolin-4-One-Based Hydroxamic Acids as Dual PI3K/HDAC Inhibitors. J Med Chem (2020) 63 (8):4256-92. doi: 10.1021/acs.jmedchem.0c00193

111. Benedetti R, Dell'Aversana C, De Marchi T, Rotili D, Liu NQ, Novakovic B, et al. Inhibition of Histone Demethylases LSD1 and UTX Regulates ERalpha Signaling in Breast Cancer. Cancers (2019) 11(12):2027. doi: 10.3390/ cancers 11122027

112. Damaskos C, Garmpis N, Valsami S, Kontos M, Spartalis E, Kalampokas T, et al. Histone Deacetylase Inhibitors: An Attractive Therapeutic Strategy Against Breast Cancer. Anticancer Res (2017) 37(1):35-46. doi: 10.21873/ anticanres. 11286

113. Meng J, Dai B, Fang B, Bekele BN, Bornmann WG, Sun D, et al. Combination Treatment With MEK and AKT Inhibitors Is More Effective Than Each Drug Alone in Human non-Small Cell Lung Cancer In Vitro and In Vivo. PloS One (2010) 5(11):e14124. doi: 10.1371/journal.pone.0014124

114. Doroshow JH, Simon RM. On the Design of Combination Cancer Therapy. Cell (2017) 171(7):1476-8. doi: 10.1016/j.cell.2017.11.035

115. Sessions Z, Sanchez-Cruz N, Prieto-Martinez FD, Alves VM, Santos HP Jr, Muratov E, et al. Recent Progress on Cheminformatics Approaches to
Epigenetic Drug Discovery. Drug Discov Today (2020) 25(12):2268-76. doi: 10.1016/j.drudis.2020.09.021

116. Whetstine JR, Nottke A, Lan F, Huarte M, Smolikov S, Chen Z, et al. Reversal of Histone Lysine Trimethylation by the JMJD2 Family of Histone Demethylases. Cell (2006) 125(3):467-81. doi: 10.1016/j.cell.2006.03.028

117. Trojer P, Zhang J, Yonezawa M, Schmidt A, Zheng H, Jenuwein T, et al. Dynamic Histone H1 Isotype 4 Methylation and Demethylation by Histone Lysine Methyltransferase G9a/KMT1C and the Jumonji Domain-Containing JMJD2/KDM4 Proteins. J Biol Chem (2009) 284(13):8395-405. doi: 10.1074/ jbc.M807818200

Conflict of Interest: The authors declare that the research was conducted in the absence of any commercial or financial relationships that could be construed as a potential conflict of interest.

Publisher's Note: All claims expressed in this article are solely those of the authors and do not necessarily represent those of their affiliated organizations, or those of the publisher, the editors and the reviewers. Any product that may be evaluated in this article, or claim that may be made by its manufacturer, is not guaranteed or endorsed by the publisher.

Copyright (c) 2021 Varghese, Del Gaudio, Cobellis, Altucci and Nebbioso. This is an open-access article distributed under the terms of the Creative Commons Attribution License (CC BY). The use, distribution or reproduction in other forums is permitted, provided the original author(s) and the copyright owner(s) are credited and that the original publication in this journal is cited, in accordance with accepted academic practice. No use, distribution or reproduction is permitted which does not comply with these terms. 